\title{
Milk, Game or Grain for a Manchurian Outpost
}

\section{Providing for Hulun Buir's Multi-Environmental Garrison in an} Eighteenth-Century Borderland

\section{David Bello}

History Department, Washington \& Lee University, USA

bellod@wlu.edu

\begin{abstract}
The long record of imperial China's Inner Asian borderland relations is not simply multi-ethnic, but 'multi-environmental'. Human dependencies on livestock, wild animals and cereal cultivars were the prerequisite environmental relations for borderland incorporation. This paper examines such dependencies during the Qing Dynasty's (1644-1912) establishment of the Manchurian garrison of Hulun Buir near the Qing border with Russia. Garrison logistics proved challenging because provisioning involved several indigenous groups-Solon-Ewenki, Bargut and Dagur (Daur)—who did not uniformly subsist on livestock, game or grain, but instead exhibited several, sometimes overlapping, practices not always confined within a single ethnicity. Ensuing deliberations reveal official convictions, some of which can be traced back to the preceding Ming Dynasty (1368-1644), regarding the variable effects of these practices on the formation of Inner Asian military identities. Such issues were distinctive of Qing borderland dynamics that constructed 'Chinese' empire not only in more diverse human society, but also in more diverse ecological spheres.
\end{abstract}

\section{Keywords}

Hulun Buir - Solon - Dagur - Bargut - agro-pastoral - hunting - Qing dynasty Manchuria - borderland - environmental relations 
Han farm and fight, so they are worn out and cowardly; the northern barbarians just herd and hunt, so they are energetic and brave. It is no contest between the two to oppose the energetic with the weak and the brave with the cowardly.

ATtRibuted TO ZHUGE LiANG (LUO 2011: 330$)^{1}$

The observation above was supposedly first penned by its famous author during the Three Kingdoms period $(220-280)$, but the assumptions about the influence of ecological conditions on human identity formation continued to resonate into the late imperial period of the Ming (1368-1644) and Qing (1644-1912) dynasties. The relationship between people, livestock, wild animals and cereal cultivars, which varied depending on climate conditions, shaped empire beyond merely its multicultural to include what I will call its 'multienvironmental' dynamics. Different relations resulted in different identities, and these identities significantly depended on the ability of the state to ensure the sustainability of the requisite sources and proportions of milk, game or grain.

This article examines some of these multi-environmental dynamics in action during the Qing establishment of the Manchurian garrison of Hulun Buir, a strategic locale near the dynasty's Russian border. Garrison logistics proved challenging because provisioning involved several indigenous groups which did not uniformly subsist on milk, game or grain, but instead exhibited several, sometimes overlapping, practices not always confined within a single ethnicity. Ensuing deliberations reveal official convictions regarding the variable effects of these practices on the formation of Inner Asian military identity as a critical human resource for the empire. While the state worked to adapt to Hulun Buir's bleak agricultural prospects, it had to take the garrison's multienvironmental dependencies on milk, game and grain into more nuanced account in order to conserve and develop the limited human resources at its disposal for sustainable borderland incorporation.

In a larger sense, Qing imperial institutions had to adapt to the environmental consequences of the dynasty's unification of Inner Asia and China proper.

1 The work's authorship is disputed and was first attributed to Zhuge Liang in the Ming period (Luo 2011: 269-71). The term 'Han' here may also refer to the armies of the Han Dynasty (206 BC-AD 220). 
Such adaptation was fraught with identity crises arising partly from conflicting pastoral, foraging and agrarian practices within Qing Inner Asian borderlands as they began to intersect intimately with China proper's more intensive types of agriculture. Elsewhere, I have discussed these clashes in terms of what I call imperial pastoralism, imperial foraging and imperial 'arablism,' which denote Qing management of environmental relations between humans and livestock, humans and wild flora and fauna and humans and cereal plants, respectively (Bello 2016). ${ }^{2}$ Here, I would like to focus on some representative complications arising from the intersection of these relations.

These complications may be abbreviated as 'milk, game or grain', to list the most critical staples for the maintenance not simply of people's biological needs, but of their identities as borderland soldiers. While grain grown locally and stockpiled by the troops themselves was the most efficient way to supply distant and isolated garrisons logistically, the specialised military skills that defined these troops instead depended on the regular pursuits of herding and, especially, hunting. Unfortunately, it was impractical to have full-time soldiers raise crops and livestock as they chased wildlife across the cold, dry grasslands at the ecologically right times of the year. It took the Qing state a decade before a combination of nature and culture compelled authorities to accept that the Hulun Buir garrison needed milk and game more than grain to remain real Qing soldiers.

The paper begins with a chronological sketch of imperial state perceptions and policies concerning the connections between Inner Asian identity and its various conditioning relations with pastoral, foraging and agrarian practices. Although the Qing imperial state came to prefer agriculture for logistical purposes, it became increasingly apparent that agriculture could denature elite troops by depriving them of formative training experience in pastoralism and foraging, hunting in particular. The case study of the establishment of the Hulun Buir garrison exemplifies the Qing state's own uncertainty when confronted with these multi-environmental complexities among its multi-ethnic soldiery within the region's ecological constraints. In the process of clarifying relations of milk, game and grain, the state came to affirm the value of hunting over that of farming for the Hulun Buir borderland garrison.

2 'Arablism' refers to refer to nature-culture interactions informing agriculture that create both material sustenance and identity. Arablism produces both farms and farmers through a range of practices as the basis for sustainable empire in China proper. 


\section{Late Imperial Contradictions Regarding Milk Game and Grain}

\section{The Late Ming: Convictions Regarding Inner Asian Carnivorous Superiority}

Meat-eating was considered a major Inner Asian advantage by officials like Su Zhigao, who served as Grand Coordinator (Xunfu) of the Ming's southern Manchurian borderland of Liaodong in 1554. Su approvingly quoted Zhuge Liang's firm division between ethnic Chinese and Inner Asian military attributes in his own compilation of past opinions and personal views on conditions along the empire's northern frontier. Su himself held that his contemporary northern adversaries' 'great strength' came from, among other things, 'meat eating'. Another Ming official, Xiao Daheng, who had also served in senior posts along the empire's Great Wall frontier, expanded on the advantages of meat eating. In his Customs of the Northern Barbarians (Beilu fengsu), Xiao, like Su, emphasised the connection between Mongol meat eating and physical prowess, but linked it to the endurance and equestrian skills required to hunt game during the steppe's harsh autumn season. He also noted that the Mongol preference for 'half-cooked' (ban shu) meat 'nurtured people's ability to endure hunger' (Su 2006: 1:230; Xiao 2006: 2:243). For both authors, meat consumption was a distinctive component of superior Inner Asian military identity.

Not all Ming officials pondering the state of the dynasty's northern borderlands could agree on the superiority of human resources derived from game and dairy rather than grain. In a report to the throne around 1621, Supervising Secretary (Jishizhong) Song Yihan disparaged his much more formidable Jurchen opponents as 'living rough, eating meat and unable to farm'. Elsewhere in his work, Su concurred that the pursuit of game had its limitations. He observed that as the Mongols, who were 'skilled at hunting', grew in numbers over time, chasing game became 'insufficient to supply them, leaving them no choice but plunder' (Chen 1997: 6:5124a; Su 2006: 1:228).

The Ming was hardly a meatless dynasty, but these sharply expressed views suggest an official stereotype constructing exclusively carnivorous tastes as ethnically distinctive fighting characteristics of Inner Asians, who were collectively referred in one entry in the official Ming History (Mingshi) as 'devotees of meat-eating' (shi rou zhi tu) (Zhang 1974: 18:5497). The views of Han Chinese officials on issues of game and grain were likely reinforced from beyond bureaucratic discourse by literary texts like Li Bai's 'Fighting South of the Ramparts' (Zhan cheng nan). Su himself briefly alludes to a significant line 
from this poem: 'The Xiongnu farm through slaughter' (Xiongnu yi shalu wei gengzuo) (Su 2006: 1:229). ${ }^{3}$

Xiao Daheng seems to have rejected an absolute position on this issue, expressing a more nuanced and accurate view of Mongols as relatively omnivorous in his work on the culture of the 'northern barbarians'. He acknowledged that it was generally held that Mongols were 'carnivorous, not vegetarian'. Xiao, too, allowed that hunting was the Mongols' 'normal livelihood', but believed that they had likely only been pure carnivores in antiquity. He realised that Mongols had indeed grown crops 'for a long time'. The main Mongol difference was that they 'relied on heaven, not on humans'. In other words, Mongols were casual cultivators who merely broadcast seed, but, unlike diligent Han farmers, did little else before the harvest to nurture their crops, which resulted in meagre harvests. This lack of intensive agriculture was why the Mongolian landscape, with its 'luxuriant grasses' and 'tall trees', was 'not like ours within the passes [i.e. China proper south of the Great Wall], with its barren hills and dried out streams' (Xiao 2006: 2:243). Throughout his discussion, Xiao suggested that Mongolian agro-foraging pursuits had significant advantages over Han agriculture.

\section{The Kangxi Reign: Burdens of Inner Asian Agrarian Inferiority}

The Ming Dynasty's most mortal Inner Asian opponents, the Manchus, likewise considered Mongol agriculture deficient. The Kangxi emperor (1661-1722), for example, was resolutely agrarian in his denigration of Mongol farming, which he felt seriously affected Inner Asian stability. In his poem, 'Beyond the Passes Outposts of Cultivation Steadily Become Settlements' (Kouwai she tun gengzhi juluo jian cheng), the emperor foresaw an opportunity to effect a 'transformation' by cultivation of both human and natural resources unprecedented in imperial history (Gugong Bowuyuan 200ob: 1:179a). Plans to develop a logistical base for the convenient supply of operations against Inner Asian threats to Qing northern borderlands certainly encouraged the Kangxi emperor's emphasis on regional agricultural development, but he was also concerned with the orderly incorporation of vast and diverse Mongol territories into the empire. The emperor considered Mongolian society in general to be riven by internal instability, most often manifested through banditry, especially livestock rustling, that was the consequence of a fragile and marginal steppe subsistence. Presiding over a capital case in 1682, the Kangxi emperor observed that the 'extremely large' number of annual banditry cases likely arose from 'the

3 Here, and elsewhere, traditional Chinese poetry is not a diversion from policy, but a dimension of it (Dai 1994; Shi 2005: 29-32). 
pressures of hunger and cold'. The solution was to 'educate Mongols' (jiaoyang Menggu in the construction of a stable order, partly founded on the development of regional agriculture, which in imperial state perspective was primitive (Yuan 1991: 483-4). ${ }^{4}$ Seventeen years of exposure to the problems of Mongolian borderland incorporation appear only to have hardened, even coarsened, the Kangxi emperor's convictions, upon which he expounded at stereotypical length in a 1698 decree on the inferiority of Mongol agro-pastoralism.

The Mongol character is indolent. Once fields are sown, they immediately go out herding everywhere. Although the grain ripens, they engage in no reaping and harvesting; nor do they gather it in when frost descends and the ears of grain drop off. Instead, this is declared a lean year. Furthermore, because of the many bands of rustlers, horses and livestock are kept nearby and penned in at night, which makes them scrawny or kills them, so that livelihoods are impoverished. Moreover, the Mongolian princes, beile, beizi and dukes all inherit their fathers' titles at very tender ages and are mostly unable to educate their subjects and keep the people in harmonious stability. Besides, their race is greedy and so must needs extort the horses, cows, knives and sashes of their subjects on sight. This thereupon leads to privation, a precarious existence and flight in all directions in search of a living ... This is why the people are all impoverished. It is an especially urgent task to determine who actually lacks a livelihood and aid them, even going so far as to advocate for the good and punish evil ... Mongolia has much drought and little rain, so the diversion of rivers to irrigate fields should be taught ... We will take a number of people from Ningxia who are able to direct irrigation and dispatch them to those places that We have gone to on northern tour, when it was observed that locales in Aukhan and Naiman have extremely fine fields where all grains can be grown ... Places in Mongolia that already have cultivation cannot herd horses where grass has not returned in abundance for many decades. So, consider cultivation, but where the grass is fine, it should largely remain, and Mongolian livestock only should rely on these herding areas ... the idleness and stupidity of the Mongolian temperament is indeed considerable, yet it is also honest and straightforward. Supervise their education properly, and such people may easily follow along.

QSL 1985-87: 5:1027B-28A

4 For use of the term 'jiaoyang Menggu' in context, see $Q S L, 1985-87: 5: 1022 a, 1048 b-49 a$. 
Agriculture lies at the core of this arablist education process, which is not intended simply to provide Mongols with enough food, but to bring out the 'honest and straightforward' elements of the Mongol character and suppress its tendency to 'idleness and stupidity'. Thus, plants and people may be mutually cultivated to embody an imperial arablist regime. An administrative structure mobilised the empire's vast human resources, dispatching groups of agricultural advisors to various Mongolian locales between 1696 and 1701 in both Khalkha Mongolia and the Six League banners. The organised shift of resources for transformation through cultivation was also continued in many aspects into the following Yongzheng reign (1723-35) (Yuan 1991: 485-90).

Agrarian pressures were similarly exerted on Manchurian indigenous peoples. One group of several thousand Warka, relocated to Ninggguta in 1676 to deny them as human resources to invading Russians, found itself unable to continue its 'normal existence' of eating fish and game, supplemented with 'only a little' agriculture. Environmental conditions in their new home compelled them 'to depend only on fields' for supply. Manchu authorities initially expressed contempt for 'these ignorant people', issuing an explicit order to ensure that when they 'go hunting, they have not been careless in cultivation'. ${ }^{5}$ These 'New Manchu' recruits were, like Mongols, subjected to an education in graniculture to minimise their collective Inner Asian foraging and pastoral inclinations.

Another form of agrarian pressure was more immediately embodied in Han migrant farmers, many of whom were authorised to take up seasonal residence beyond the Great Wall from almost the onset of the Kangxi emperor's tenure in the early 166os (Zhang 2003: 36-8). Official concerns to avoid inter-ethnic conflicts that could arise from clashes over limited resources for herding or farming or simply from cross-cultural miscommunications eventually resulted in the closure of Mongol steppe areas to further such agrarian expansion in 1748.

\section{The Qianlong Reign: Contradictions of Inner Asian Cultivation}

Managing the steppe as a multi-environmental jurisdiction was quite complicated, as exemplified by a $175^{2}$ Manchu memorial by a herd official, Heking, from the Chakhar pastures just north of the Great Wall. He began with what might be called a local variant of jiaoyang Menggu intended to educate Beijing officials. Heking pointed out that Mongol livestock depended on pastures for survival 'just as, to make a comparison, the Han commoners of the interior depend for survival on fields and grain'. Existing statutes on grassland fires, however, heavily fined Mongol offenders, who paid in livestock, while Han commoners

5 NFY, KX 1-1676: 120-25. 
guilty of the same offence received only the 'comparatively light' punishment of blows from long bamboo paddles of varying weights. Consequently, Han were 'careless with fire and charcoal and do not take precautions, which results in setting fires that burn up the grasslands of the herding pastures'. On the basis of the dynastic principle that 'those within and beyond the passes are all Milord's servants, with no distinction between Han commoner and Mongol', Heking requested that Han commoners who set fires be fined as Mongols, with livestock payments converted into a monetary equivalent. ${ }^{6}$ Here, a tension between dairy and grain across an ethnic boundary was resolved in favour of the former, a decision that might have gone the opposite way under the Kangxi emperor. As an official and multi-environmental recognition of milk's legitimacy, the 1748 ban constituted an environmental watershed.

No later than the Yongzheng period the state had realised, in large measure through instructive local demonstrations like Heking's, that the integrity of Mongol herding zones, which remained the cores of Mongol livelihood, was endangered by minimally restricted Han agrarian settlement. Industrious Han could easily, as a 1730 decree put it, 'hem in pastoral areas' if their agricultural machinations were not policed. Although his reign saw further consolidation of existing Han settlement in Mongol grasslands, Yongzheng's court also began to restrict further agrarian access and development in order to protect pastures (QSL 1985-87: 8:311a-b). This trend continued, and intensified during the succeeding Qianlong reign (1736-96), culminating in the 1748 ban.

Writing almost a century after his grandfather had issued the 1698 decree, the Qianlong emperor, in a 1782 poem entitled 'Mongolian Fields', depicted Mongols who no longer 'depended on heaven' for a harvest, but were fullfledged Han-style arablists:

All are accustomed to the tasks of the plough.

They consider rain and assess fair weather,

Having worries no different from common farmers,

And so actually abandon herding and hunting,

Thus, forgetting their origins

GUGONG BOWUYUAN 2000A: 14:167B-168B

6 MWLF, QL 17/11/29 [03-171-0378-018]. Bejing seems to have learned Heking's lesson. Within a year of his memorial, a statute revision appeared to the effect that: 'Henceforth, all people of the interior who go beyond the passes to trade and carelessly permit fires to spread to herding pastures will all be fined livestock in accordance with the Mongol statutes on fires started by using them to smoke wild animals from their lairs. Those without livestock will be fined in an equivalent value of silver' (Zhao 2006: 167). 
At this point, jiaoyang Menggu seems to have succeeded only too well, from the Qianlong emperor's retrospective, and certainly greatly exaggerated, point of view. During his reign, an imperial pastoralist order, including a system of disaster relief, adjudication of regional disputes, delineation of pasture boundaries, supervision of livestock reproduction in state herds and consolidation of agro-pastoralism in select areas, had become well established in Qing Mongolian territory. Under these more stable conditions, the priority shifted from 'educating Mongols' to preserving an endangered pastoral resource, Inner Asian cavalry, against arablist pressures. Preservation would ensure protection of critical military skills associated with traditional herding and hunting from the erosive effects of cultivation practices constitutive of China proper and its Han majority. The Qianlong emperor was clearly disturbed by the consequent potential for assimilation by cultivation. Further on in 'Mongolian Fields', he elaborated on his dismay at the inadvertent consequences for Mongolian imperial identity that a Qing pacification of the empire's northern Inner Asian borderlands precipitated:

In Qinghai, it is worse.

They drink and sleep peacefully at ease,

Disinclined for fields, game, herds and all.

They even fear robbery from the poor tribals.

Yet the ways of places are not all the same;

Take that of the Inner [Mongolian] jasaghs:

Food and clothing steadily mount in abundance and

They peacefully reside in mud-brick dwellings.

What divergence in their wending towards the Han multitudes?

There is the subtle apprehension that if they are deployed,

Can they be of the stuff their ancestors were?

GUGONG BOWUYUAN 2000A: 14:167B-168B

The first four lines here are likely a reference to growing conflicts between Tibetan peoples in northern Qinghai and Mongols who had once dominated them, but now, as a gloss explained, had to be admonished by local Qing officials to remember their old ways (Gugong Bowuyuan 2000a: 14:167b-168b). ${ }^{7}$

7 Tensions between Mongols and Tibetans flared up in the late Qianlong period. In 1791, for example, the Governor-General of Shaan(xi)-Gan(su) reported trouble from 'wild Tibetans' (ye fan), who 'had never sown, but hunted for a living and, moreover, lacked a fixed abode'. They plundered Mongol livestock and colluded with Mongol bandits (Zhe-cang 1994: 16-18). 
The poem's remaining lines demonstrate, however, that the solution to such an Inner Asian identity crisis could not be an agrarian one. The nearest Mongol neighbours of the Qing, the Jasaghs of the Forty-Nine Banners of the Six Leagues, had become too agricultural for state comfort. Another gloss contextualises the two final lines as a reference to the disastrous Ming defeat in the Battle of Tumu 1449, when the Yingzong emperor (ruling as the Zhengtong emperor from 1435-49) lost an entire Chinese army and was captured by a much smaller Oirad Mongol army. This defeat conferred an exaggerated impression of Mongol prowess on Ming observers of the northern frontier, which formed the historical context of sixteenth- and seventeenth-century officials' perceptions, like those of Su Zhigao and Xiao Daheng (Gugong Bowuyuan 2000a: 14:167b-168b; Liu 2006: 261).

The Tumu Crisis, also known as the Battle of Tumu, left a different sort of impression on the Qianlong emperor in this poetic context. Lines from 'Mongolian Fields' express 'a subtle apprehension' that his own Qing Mongols could not achieve a comparable victory, mainly because of the Qing arablist achievement of transformation through cultivation. The emperor explains further in an extended commentary that the Ming Yongle emperor (r. 1402-24) had effectively deployed his own Mongols, from the Uriangkhad Three Commanderies (Wu-liang-ha sanwei). Once 'territory [north of the Great Wall] had been ceded as compensation' for their military service, however, 'later [Ming] generations were unable to control them', which led ultimately led to the Tumu Crisis. Yet, when 'inner (China proper) and outer (Inner Asia) became one family' as a result of the Qing conquest, these Mongols were all

ploughing diligently [and] formed into households, becoming indistinguishable from the Han masses. These Mongols of the present are truly not comparable to those feared by the Han, Tang and Ming. On the contrary, should they participate in a campaign, I fear they would lack the strength to wage it.

GUGONG BOWUYUAN 2000A: 14:167B-168B ${ }^{8}$

Qinghai Mongol pastoral strength had been in decline ever since the abortive Lobsang Danjin revolt of 1723-24. Mongol weakness, which worsened in the nineteenth century, was a reversal of conditions from the early sixteenth nearly into the mid seventeenth centuries when Mongols moving into northern Qinghai had pushed indigenous Amdo Tibetans south of the Yellow River (Cui et al. 2010: 362-76).

8 These Mongols had surrendered to the Ming and were used to replace Han garrisons beyond the Great Wall, roughly centred on Qiqihar, in 1403 (Chan 1988: 222-3). 
Such anxieties fundamentally distinguish the Qing from most of its imperial predecessors, especially the Ming, whose writers may have admired and even exploited Mongol military prowess, but would never want to nurture it on milk, game or grain.

Yet Qing views of Mongols were conflicted, as another of the Qianlong emperor's poems exemplifies. The commentary to his 'Poetic Record of the Reception of the Mongolian Nobles' Arrival' (1778), a work that showcases Mongol tributary submission to Qing rulers, expressed satisfaction in the Manchu accomplishment of Mongol transformation through cultivation. In this context, the decline in Mongol herding was not a cause for worry, but for pride: 'recently, each tribe has already absorbed the cultivation practices of China proper and no longer exclusively engages in herding. The vast extent of the state's enriching educational influence (jiaoyang zhi ze) is thereby manifest' (Gugong Bowuyuan 2000a: 13:11b). This education was explicitly Han and not just agrarian, as the emperor shows in a gloss on another of his poems, 'Country Inns' (Ye dian, 1783). The poem's main theme is an expression of imperial satisfaction with the Han agrarian cultural development of Bagou, a former Khorchin Mongol herding and hunting area. The gloss emphasises that, after a century of settlement by economically distressed Han commoners, the area now boasted 'people who study for the civil service exams' (Gugong Bowuyuan 2000a: 14:282a-b). Considered together, the Qianlong emperor's poems on Mongol culture reflect the Manchu state's own equivocal position on the interaction between Chinese and Inner Asian agrarians, pastoralists and foragers in the process of borderland consolidation.

Qing authorities did accept some practical limit to the Inner Asian borderland's transformation through cultivation, if for no other reason than the constraints of regional ecological conditions on farming. During the dynasty's resettlement of the Torghuts after their return trek from Russia in 1771, for example, a sustained and deliberate state attempt was made to convert them from pastoralism to agriculture, mainly in order to demilitarise what the throne saw at the time as a potentially disruptive group of wild Mongol newcomers not yet domesticated by the harness of imperial pastoralism. This attempt failed due to a combination of factors, inhospitable steppe climate conditions for sufficient and stable agrarian development being the primary problem (Bello forthcoming). Qing authorities were well aware that such problems did not exclusively arise from human culture, as the Qianlong emperor went on to acknowledge in another series of stanzas from 'Mongolian Fields':

The Khalkha [Mongolia] lands are cold;

There are no means by which to serve the plough. 
So, diligence in herding and hunting persists and

The old ways are not yet gone.

GUGONG BOWUYUAN 2000A: 14:167B-168B

Here, climate plays a primary role in the preservation of a borderland pastoral and foraging ethnic identity that serves as a critical imperial human resource. By freezing out agriculture of a sufficient scale, the more northerly reaches of the Qing realm 'naturally' favoured the herding and hunting that, through dynastic management as imperial pastoralism and imperial foraging, produced the requisite human resources for elite dynastic military strength. The interdependency of ethnic identity and ecology is reinforced by a gloss on the next line: 'Those newly subjected know the plough', which is a reference to newly subjected Dörbed, Khoshot and Torghut Mongols, who are 'all Oirads accustomed to cultivation. The climate (qi) scattered throughout their lands is comparatively warm where they reside, which thus serves ploughing and herding' (Gugong Bowuyuan 2000a: 14:167b-168b).

There could be no absolute dichotomies applicable to Inner Asian environmental relations to milk, game and grain. The Qing conquest certainly altered late imperial Chinese perceptions of these relations from what they had been during the Ming. Yet a state inclination towards imperial arablist policies persisted, even if it by no means always prevailed, that tended to support administrative assumptions that regional environmental relations were wholly malleable. Indigenous hunters and herders could simply be taught or ordered to farm. Regional diversity, however, arose from a combination of human culture and non-human nature that were by no means always so pliable. As long as different Qing humans relied on different combinations of animals and plants in different locales, the Qing state would have to adapt to the consequent environmental diversity that had come under its ostensible authority as it consolidated the unification of Inner Asia and China proper.

The eighteenth-century dynastic garrisoning of the strategic Hulun Buir grasslands in what is today northeastern Inner Mongolia-or southwestern Heilongjiang during the Qing-exemplifies Qing state adaptation to the environmental imperatives of milk, game and grain that informed a diversity of Inner Asian borderland identities. These imperatives rendered the implementation of state policy in a strategic borderland territory conditional on elements that were neither exclusively cultural nor exclusively ecological. Instead, it was the interrelation of these elements as 'environmental' that precluded a straightforward consolidation of Hulun Buir in the monocultural agrarian terms initially contemplated by dynastic officials primarily interested in developing stable sources of local supply. 
The Hulun Buir garrison was entirely Inner Asian, composed primarily of Solon-Ewenki, Dagur and Bargut peoples indigenous to the Manchuria of the period. ${ }^{9}$ As some officials had to discover, however, they were not all herders, hunters or farmers, nor could these diverse groups simply be converted to agricultural livelihoods en masse to suit the more uniform requirements of imperial logistics. Instead, authorities had to adapt to the garrison's 'multi-environmental', as opposed to a multicultural, character, composed of Solon-Ewenki and Bargut pastoral-foragers and Solon-Ewenki and Dagur agriculturalists.

\section{Sorting Out Garrison Relations of Milk, Game and Grain}

\section{Ecological Parameters of Garrison Establishment}

The recent work of Mongolian scholar Bao Meihua has made a major contribution to research on the eighteenth-century history of the Hulun Buir garrison, primarily through her exemplary study of its extant Manchu record. This includes a thorough narrative focus on the garrison's multi-environmental challenges related to milk, game and grain (Bao 2012). ${ }^{10}$ In this section, I refine and expand on these aspects of her study to focus more analytically-including consideration of pertinent environmental science literature-on their implications for Qing regional borderland policy conceived of as the management of environmental, rather than of simply human, relations. The first two subsections examine the constraints of both nature and culture on initial dynastic plans to establish an agricultural basis for the garrison. The next two subsections examine the institutional resilience of imperial foraging and the institutional limitations of imperial arablism, respectively, in the region's borderland context. The final section focuses on state recognition of the necessity to adapt to the garrison's preferences for game over grain to preserve military human resources.

The immediate reasons for the establishment of the garrison were driven by very human security concerns. The contemporary threat from the Oirad Zunghar Mongol confederation provided some immediate motivation, but the main long-term issue was to 'protect the direct route from Russia' into

I have usually followed Janhunen (1996) for the always problematic transliteration and correlation of regional indigenous ethnonyms, employing a single modification to distinguish the 'Solon' of Qing records in more current classification terms by adding the suffix '-Ewenki'. For ethnographies, see Janhunen (1996: 50-52) (Dagur); (1996: 93-4) (Bargut); (1996: 101-2) (Solon-Ewenki). 
Manchuria. ${ }^{11}$ Nevertheless, local ecological conditions exerted a strong influence over these human concerns from the initial deliberation and establishment of the Hulun Buir garrison in 1731-32. All authorities involved were aware of the multi-environmental relations that informed the multi-ethnic garrison of 3000 Solon-Ewenki, Dagur and Bargut. The area first considered at the mouth of the Jirmatai-Hailar rivers' confluence was attractive because it was 'fine and vast in all directions. It is possible both to cultivate fields in and build a walled enclosure on. Grassland and water are good with abundant trees and forest and plentiful hunting and fishing.. ${ }^{2}$

Agro-pastoral concerns informed the selection of the garrison site. Local Mongols, consulted as to the best location, were doubtful about the Jirmatai area, where they said frost could fall early as early as the sixth month, so the settlement was ultimately constructed in Hailar. People were eventually sent out to conduct test cultivation and sowing commenced in spring of $173^{2}$. In the meantime, an initial temporary settlement would be established for the garrison, and herding would begin without delay. A subsequent 1732 report on six test locales where barley, wheat, oats, millet and buckwheat had been sown stated all were affected by drought. Half the locales were thus expected to achieve no more than a $5^{\circ}$ per cent harvest if sufficient rainfall resumed. It also noted that half the test areas were too close to the (Greater) Hinggan Mountains, an area normally subject to comparatively early frosts. Despite limited prospects for cultivation, testing was ordered to be continued in all locales. ${ }^{13}$

These very unfavourable agricultural conditions were the first ecological obstacle encountered by the garrison, and certainly persist into the present. One recent evaluation of general conditions in the 'agro-pastoral mosaic zone in north China', which begins in the northeast in Hulun Buir, concluded that the region's overall ecological conditions were 'brittle and sensitive, risky for agriculture' (Zhang et al. 2007: 20). Complex dynamics between air temperature and precipitation, which in turn affect soil quality, mainly account for the region's agricultural fragility. Hulun Buir's average annual precipitation of $339 \mathrm{~mm}$ and mean annual temperature of $2.2^{\circ} \mathrm{C}$ make it very difficult even

11 MWLF, YZ 10/3/28 [03-171-0318-008]. My reference system for Manchu documents is based on the Manwen lufu zouzhe (Grand Council Manchu-language reference collection) archive's current digitised organisation, which was not yet established at the time of Bao's 2012 dissertation.

12 MWLF, YZ 10/3/28 [03-171-0318-008].

13 MWLF, YZ 10/4/21 [03-171-0318-009]; Guan \& Qu 1998: 2:2142, \#4129. The range is also transliterated 'Khingan' from the Mongolian. 
for crops adapted to comparatively cooler and drier conditions, such as spring wheat varieties, to grow. Spring varieties are generally sensitive to frost, and temperature requirements for both winter and spring wheat to grow properly are around $5^{\circ} \mathrm{C}$ (Liu et al. 2014: 2; Asseng 2012: 92). While buckwheat is better adapted to poor soils than most other crops, it too is not frost tolerant (Pavek 2016). Wheat, barley and oats all require between about $450 \mathrm{~mm}$ and $650 \mathrm{~mm}$ of precipitation during their seasonal growth periods (Brouwer \& Heibloem 1986: 2.4). Hulun Buir's agricultural conditions are unusual even in terms of the regional agro-pastoral mosaic. One 2014 study of regional vegetation biomass concluded that there was more vegetation below ground, as root systems, than above it (about 15 times more), the inverse of the ratio found in more temperate Inner Mongolian grasslands further south and west, some of which were under comparatively stable cultivation during the Qing (Liu et al. 2014:4).

Yet it remained just possible to find an arable patch within these generally forbidding conditions. Of all Hulun Buir areas subject to test cultivation, the Geni River zone proved to be the most promising, and a sustained effort was made only there. ${ }^{14}$ Geni River would, nevertheless, eventually prove fruitless as well. The region's agricultural project failed in large measure because of ecological dynamics that present challenges to steppe cultivation quite different from those of the alluvial plains of China proper, the foundation of imperial agricultural experience.

One of these dynamics is erosion. Unlike China proper, for example, the northern grasslands experience comparatively little water erosion, but are instead subject to serious aeolian erosion, especially when soil surface is disturbed, from a combination of strong winds and aridity. Activities like deep ploughing exposes subsurface sand layers that can develop into 'blowouts' extending for dozens of metres to form dunes measuring hundreds of metres. Such dunes can eventually cover up to eight times the grassland area destroyed by the initial blowout. Consequently, 'cultivation of these grasslands was risky and leads to degradation or even disappearance of original grassland vegetation on a large scale, and to the total destruction of soil and grass roots layer ecosystem' (Zhang et al. 2007: 21). Unsustainable agricultural development can not only undermine farming, but pastoralism and foraging as well, because the vegetable roots of all these practices are literally eradicated. Opportunistic exploitation of grassland soil's potential for cultivation would eventually render it useless for any environmental relation the Qing relied upon for borderland incorporation. 
Conversion of grassland to cropland totally destroys the grassland ecosystem's function. Cropping on dry and semi-drylands may bring in relatively high production in a short period. But this can only be achieved at the expense of the rapid soil fertility depletion, soil erosion, and lasting and difficult-to-control sandy desertification. In other words, cropping in arid and semiarid areas is a form of mining of nutrients and organic matter and the economic gains are short lived and are at the expenses of sustainable development in the long term.

ZHANG ET AL. 2007: 24

Such ecological limits are likely the main explanation for the Mongolian 'cultural' practices of 'relying on heaven' for a harvest, so decried by Ming officials and Qing emperors. Even Mongols, however, attempted no serious cultivation of Hulun Buir before the arrival of Qing forces. It certainly remains unclear the extent to which any of the people involved understood, or were able to convey, the full range of Hulun Buir's agrarian challenges. Yet locales like Geni River, nevertheless, made agriculture seem just viable enough to those urban officials inclined to rely on cereals as the main staple of garrison supply.

\section{A Multi-Environmental Garrison}

In very nominal terms, the personnel originally recruited for the Hulun Buir garrison were drawn from the foraging reserves in southern Heilongjiang, whose skills made them ideal soldiers. ${ }^{15}$ These reserves were quite diverse in their subsistence pursuits. Of the four main ethnic groups that made up the foraging reserves, the Dagur were generally acknowledged to rely primarily on farming for their livelihood. Farming Dagur are especially visible in Russian records of encounters with the 'Daur' (i.e. Dagur) living along the Shilka River, that stretch of the Amur River (M.: Sahaliyan Ula, C.: Heilongjiang) flowing into Qing territory from the west. ${ }^{16}$ The other three groups, the Solon-Ewenki,

15 Terminological distinctions between various Qing military formations of Manchurian borderland peoples are complex and not completely consistent. Generally speaking, the term 'New Manchus' (C.: xin Manzhou; M.: ice Manju) could be applied to any indigenous groups formally mobilised as a dynastic unit on regular pay and provisioning from their previous status as unstipended tributary forager reserves, who could be called 'hunting' (C.: bu-te-ha or dasheng; M.: buthai) formations. Although often conventionally termed the 'Hunting Eight Banners' (C.: Bu-te-ha baqi), I consider formations like those comprising the Hulun Buir garrison as mobilised 'foraging reserves' on the basis of Manchu documents like MWLF, QL 1/12/11 [03-174-1481-001] and MWLF, QL 1/1/22 [03-0172-668-001].

16 See, for example, a c. 1641 report to the Tsar, stating that 'many settled Daur agricultural people live along the Shilka ... and grow the same kind of grain as Russians do' (Dmytryshyn et al. 1985: doc. \#59, 186). 
Bargut and Orochen, were considered hunters for their normal subsistence. There are many Manchu documents, however, indicating the Dagur were also hunters not highly skilled in farming.

In the year of the garrison's conception in 1731, the military governor of Ningguta (Jilin) issued a complaint about Solon-Ewenki and Dagur sable-pelt poachers. In 1747, 'foraging (M.: buthai) Solon-Ewenki and Dagur, living 'intermixed with military personnel' near the garrison town of Mergen, brought tribute sable to Beijing', where they caused some trouble while buying slaves. Decades later in 1791, a group that included Solon-Ewenki and Dagur from 'the foraging zone' (M.: buthai bai) in the Non River (Nenjiang) region, were taken to task for a shortfall in their sable-pelt trapping quota, which had been affected by a major snowfall. ${ }^{17}$ The region was a site of large-scale relocations of multi-ethnic 'Solon' peoples from the north during the mid seventeenth century under pressure of Russian incursion and constituted a major dynastic military reserve (Han 2011: $145^{-6)} .^{18}$

It is evident from these examples, which extend over 60 years, that the Dagur were not uniformly agricultural, and that the agriculture they did practise could be of the casual 'Mongolian' type imperial China generally associated with primarily pastoral and foraging peoples. Apparently, however, in 1742, after a series of reports and inquiries, dynastic authorities discovered that 675 Solon-Ewenki troops and 720 Dagur wanted to move out of Hulun Buir and 'live in Ombuci in shelters and cultivate fields for a living'. ${ }^{19}$

Even before this date, the environmental relations of the garrison had been an absorbing focus of administrative attention. The initial relocation of 1636 Solon-Ewenki, 730 Dagur, 359 Oronchen and 295 Bargut from the jurisdiction of Qiqihar to the east was accompanied by an enormous herd of 15,734

17 Guan \& Qu 1998: 2:2037, \#3782; MWLF, QL 12/8/12 [03-0174-1484-004]; MWLF, QL 56/6/o8 [03-0194-3340-028]. It is conventional to translate the Manchu buthai, and its Chinese transliteration bu-te-ha, as 'hunting'. Bu-te-ha can also refer to the Non River region (today split between the Inner Mongolian Autonomous Region and Heilongjiang Province) that appears in Manchu documents as 'buthai ba'. Manchu documents show that men designated as 'huntsmen' (M.: butha i haha) could nevertheless be officially engaged in honey gathering and ginseng digging; MWLF, QL 1/1/22 [03-0172-668-001]. Hence, my translation of buthai and its variants here and throughout as 'foraging'.

18 'Solon' could also be a multi-ethnic reference to indigenous peoples (Zhang 1965: 2429).

19 MWLF, QL 7/3/19 [03-172-610-005]. Bao concludes that, including youths and recruits of unknown ethnicity, troops finally numbered 4170 and may have had as many as 20,000 dependents in their accompanying households (Bao 2012: 30). It has been asserted that such unprecedented numbers effected an environmental transformation of the region (Qi 2001: 61; 'Liu Zeming' 1993b: 576-84). 
horses and 95,140 sheep, driven in from the main imperial pasture complex of Darganga in what is now northern Inner Mongolia. These figures constituted about 65 per cent of the horses and 95 per cent of the sheep grazing this vast area at the time. In addition, they would be granted silver, totaling 48,670 taels, sufficient to purchase 9734 milch cows. This was to ensure each trooper five mares, three milch cows and 30 ewes, in addition to providing larger livestock grants to their officers. ${ }^{20}$ Herding, however, would not be free range, but conducted within the strictures of imperial pastoralism, which not only closely managed livestock mobility, but that of livestock herders, who might also engage in foraging, as well.

Because the pastoral residence area for the four banners of the left wing is very close to the Russian border, [banner wing] Superintendents must keep their subordinates well under supervision, to strictly prohibit crossing the fixed bounds to hunt, raid, quarrel, etc., so as to absolutely ensure a harmonious existence and prevent the outbreak of incidents. ${ }^{21}$

Despite the obviously nuanced approach they took towards the diversity of the garrison, officials tended to assume that there were direct correspondences between ethnicity and environmental relations for many administrative purposes. Ethnic ties to either animals or plants even determined how the troops and their households would be relocated. Sometimes this meant finding sufficiently diversified space for multiple environmental relationships among a single group. In 1731, newly formed and relocated Uriangkhad banner companies were raising livestock 'normally' in their new pastures, but there were no adequate hunting grounds nearby. After paying over an extra silver subsidy, dynastic authorities decided to move them again to Heilongjiang locales in Qiqihar (Ma.: Cicigar), Sahaliyan Ula (Ch.: Heilongjiang) and Mergen, where conditions could accommodate both herding and hunting side by side. In Hulun Buir, 2400 'New' Bargut troops could be introduced into the garrison in 1734 because there were adequate pastoral lands available to accommodate them, although these had to be carefully delineated to avoid conflict with existing 'Old' Bargut and Solon-Ewenki pastures (Bao 2012: $\left.77^{-80}\right) .{ }^{22}$

\footnotetext{
20 MWLF, YZ 10/4/21 [03-171-0318-009].

21 MWLF, YZ 10/4/21 [03-171-0318-009].

22 Guan \& Qu (1998: 2:2036, \#3869). It has been argued that the ensuing reduction in pastoral mobility was the result of a deliberate Qing programme to domesticate these Mongol peoples politically and militarily ('Liu Zeming' 1993b: 579-80). Relocation was probably conducted in part because 2000 of the original Hulun Buir garrison had been deployed to
} 
Different dynamics between pastoral and agricultural relations had influenced garrison deployment from the first, when it was decided that, 'being versed in pastoralism', the Solon-Ewenki and Bargut would transfer their own households from the foraging zone to Hulun Buir. In contrast, the Dagur, who 'build homes and make their living by cultivation', would send men ahead to build a walled settlement and get fields started. Once these were established, the rest of their households would join them. ${ }^{23}$

Consultations with local Mongols had already suggested that the first wave of soldier-farmers would receive a cold welcome in the form of early frosts at Jirmatai. They advised building a temporary walled settlement and suggested test cultivation of the area for one to two years. If harvests were sufficient, a more permanent settlement would be built and cultivation expanded. ${ }^{24}$

There seems to have been a persistent state commitment to constructing an enduring agricultural foundation for the garrison despite continual indications that the most sustainable environmental relationships available to dynastic authorities were pastoralism and foraging, given the environmental resources, human and ecological, at their disposal. These two alternatives certainly had their own limitations, even in Heilongjiang. Livestock problems can be glimpsed in November of 1732, when a transfer of military personnel from Sahaliyan Ula and Mergen to Qiqihar ran into storms that left roughly two to three feet of snow blocking the routes. A hard frost soon followed, with the result that

... since all is covered by this large snowfall, the troops will be without dung or grass for fuel and will ride horses all day in snow without obtaining any pasturage at night. This is impossible. Carts have been bogged down by the snow and are difficult to move and the oxen pulling the carts during the day can get no pasturage at night. Having to spend the night in snow is even more impossible. If an attempt is made to brave the storm, the horses and oxen will be decimated, which will result in the loss of the provisions they are carrying, with serious implications. ${ }^{25}$

Khalkha Mongolia in 1733 as reinforcements, but the main dynastic motive was to separate the New Bargut from their oppressive Khalkha overlords, which would avoid internal disturbances in this strategically threatened borderland (Fu-heng 1990: 1:55ob; 'Liu Zeming' 1993b: 587-90). 
Authorities relented, deciding to wait until the 'grass sprouted' the following spring, when the troops' livestock could be more easily shifted. Such weather is likely to have limited foraging for game as well, since the requisite horses could not be properly pastured for an uncertain, but likely extended, period of time. Difficulties of military transfers even within the province, often caused by forbidding terrain and climate, were one of the main reasons it was desirable to have troops provide their own supplies locally. The interconnections between humans, livestock, grass and climate so concisely summarised in the brief passage above convey much of the environmental complexity with which dynastic operations had to contend in western Heilongjiang. Indeed, by 1743 , the garrison's herders had experienced at least one serious loss of livestock to a major snow storm disaster. ${ }^{26}$ Nevertheless, some quantity of livestock was required, regardless of whether people foraged, herded or farmed, and this dependency meant that the distribution and availability of grassland and water resources set certain, although certainly not insurmountable, limits to dynastic agency.

Despite their logistical preference for grain under many borderland circumstances, dynastic authorities were generally convinced that Inner Asian soldiers were not the best cultivators and that their military skills would deteriorate if they stopped foraging and devoted themselves exclusively to farming. Prior to the conquest of China proper in 1644 , there was still a basic, if not absolute, division of agrarian and military labour along ethnic lines within the Manchu state. Generally speaking, Han Chinese farmed; Inner Asians fought. This division sought to reduce the tensions between imperial Manchu existential dependence on milk, game and grain inherent in their interaction with Han Chinese. Hong Taiji (r. 1627-43), for example, reminded his banner company commanders in 1633 that Han livelihoods were dependent on fields and so were part of 'the state's great policy ... to encourage agriculture and train for war'. The corresponding contribution of his Manchu vassals was 'lead your subjects young and old to make diligent and continuous practice of archery, spring, summer and fall ... [for] this is the art of our state that subdues for victory' ( $Q S L, 1985-87: 2: 179 \mathrm{~b})$. Within a few years after the final Qing completion of the conquest in the early 1680s, however, the throne was praising Mongol, Dagur and Solon-Ewenki for working fields in Heilongjiang to supply personnel manning the territory's military postal relay stations ( $Q S L, 1985-87: 5: 372 \mathrm{a})$.

Logistical concerns put pressure on borderland military forces best alleviated by the stockpiling of grain reserves, which did not need to be chased down. Pursuit of game, however, was the essence of elite military training that kept

26 MWLF, QL 25/8/11 [03-178-1834-038]. 
critical skills like archery sharp. Moreover, duty in outposts like Hulun Buir was too far from logistical centres to be supplied reliably and economically with grain. Finally, even if local ecological conditions permitted cultivation on site, the rigours of Han-style intensive cultivation demanded too much time that would have been better devoted to military training.

\section{The Core of Imperial Foraging Affirmed}

Contradictions between farming and training were apparent almost from the inception of the garrison. As early as the winter of 1732, the Yongzheng emperor shared the concern of senior garrison officers that, if test cultivation was handed over to the Hulun Buir garrison, it would 'definitely have an adverse effect' on military training. Instead, he ordered that 500 boatmen and way-station personnel, at least some of whom were Han, be brought in from Mergen, Aigun and Qiqihar to farm for the garrison the following spring, during which time they would be supplied with grain rations $(Q S L, 1985-87: 8: 622 b) .{ }^{27}$ Such pressures seem endemic to regional borderland environmental relations. A report from the Mergen by Vice Banner Commander Dokini the following year stated that 'there was a great deficiency in cultivators' in the wake of mobilisations of over 1500 of the town garrison. In the process of trying to consolidate households for more efficient farming, Mergen officers discovered 189 households comprised exclusively of 516 women and children. 214 of them were too old or too young to work the land without their men, all of whom had been mobilised. ${ }^{28}$ The state could clearly exhaust its carefully cultivated human resources to destabilise agriculture in its Manchurian borderland, where these resources were at a premium.

Another 1733 report from the foraging zone reveals in detail the steady erosion of forager reserves and skills under the continual demands of imperial borderland consolidation. Out of an original 66oo-plus able-bodied SolonEwenki male reservists whose original obligation was the semi-ritualised annual presentation of sable-pelt tribute to the throne, 1303 had been mobilised as full-time soldiers. They were duly released from this tribute and dispatched elsewhere in 1729. Their departure required the suspension of tribute obligations for a further 1000, who were to look after the mobilised men's households.

27 After further deliberation, some inactive reserves in Hulun Buir were included to make up the total of 500 cultivators (Bao 2012: 42-3). See MWLF, YZ 10/3/28 [03-171-0318-008] for evidence that some of the designated cultivators were Han, who had been manning waystations (tai) intended to protect travellers and facilitate communications on the route to Mukden. 
Nearly all the remaining men were deployed to regional garrisons: 3141 to Hulun Buir; 1018 men to the Būrde region to augment test cultivation in Geni River; 31 deployed to the military postal relay stations. With 168 kept busy cultivating state fields, there remained only ' 134 Solon and Dagur to trap tribute pelts'. The author of the report, Soju, warned that 'as there are now so few people to engage in hunting, over time experienced people will gradually disappear, young people will no longer understand foraging (M.: buthašame doro) and the old ways will be forgotten'. Despite his concerns, Soju had written the memorandum to request that the 1000 men looking after the households of their mobilised comrades be either returned to pelt trapping for tribute or mobilised into the army themselves. He recommended an annual stipend of three taels of silver as an adequate provision for families to replace their providers. A deliberation of his proposal acknowledged that the 1000 men thad become lazy. Once they become accustomed to this situation, it will mean the end of the old methods for driving animals from their lairs and killing them, which will also be of no benefit to their livelihoods'. These men were duly authorised once more to 'submit the normal tribute' of sable pelts to preserve their foraging identity as a human resource in reserve for Qing armies. ${ }^{29}$

A third 1733 report by a censor, Jangkige, on inspection in Qiqihar, Sahaliyan Ula and Mergen reveals the economic costs of military mobilisation for the regional grain market. Jangkige submitted his memorial because he was struck by high cost of grain, more than 10 silver taels per shi, in the region. When he asked locals about this, they said that

there were numerous cultivators the previous year, which was a good one. The price, also augmented by grain harvested by Mongols on sale, was only $2.4-.5$ silver taels per shi. Twice, in 1729 and 1731, the army was deployed and available youths were taken and made into troopers' retainers, filling positions for 3000 soldiers. There are now few troops engaged in cultivation, so that since all make food purchases, the price of grain steadily rises until it has reached 10-plus taels. ${ }^{30}$

Accounts like those of Dokini, Soju and Jangkige define the operation and contradictions of imperial foraging, the Qing management of Manchuria's primary environmental relations between people and forest ecology for purposes of borderland incorporation and construction of elite troops. Foraging, which appears here as mainly a relation between humans and game, was critical in

29 MWLF, YZ 11/11/19 [03-171-0193-022].

$30 \quad$ MWLF, YZ 11/7/27 [03-0171-0167-010]. 
imperial terms as the most effective way to produce these troops, who were then exported across the empire. A contradiction arose within this mobilisation that left them no time to provision themselves through hunting, which did not just feed them, but, most importantly, honed their military skills. The standard Han practice was to have troops farm for their own support, but, as Zhuge Liang noted as far back as the Three Kingdoms period, agriculture was believed to sap imperial military identity, rendering it inferior to more carnivorous Inner Asian adversaries who spent their peacetime on surrogate military duty in the saddle and on the hunt. The testimonies of Dokini, Soju and Jangkige provide detailed Qing examples of how this disparity between game and grain could come about.

\section{The Limits of Imperial Arablism Tested}

Test cultivation during the garrison's first year, however, was unsuccessful, mainly for ecological reasons of freezing climate at every site but Geni River. Another reason was a related problem of supplying auxiliary manpower sufficient to sustain cultivation at the four other test sites being worked in late 1733 . The grain expended to continue to feed these farmers and supply them with seed was considered a waste. In their normal capacity as boatmen, they were all expected to grow their own grain locally. Their deployment to the test sites made this impossible, especially because it was difficult to provide for their dependents and to fulfill their regular transport and communications duties from such a distance. ${ }^{31}$

So even relatively arable Geni River required heavy start-up costs in terms of manpower and grain supplies brought in to sustain the cultivators as they worked to achieve a sufficient harvest. Fengtian's Military Governor, and temporary acting Military Governor of Heilongjiang, Nasutu evaluated the situation in December of 1733. He also wrote another report of the same date when he led 1000 Dagur troops on a comparatively short trek from their garrison at Bürde to Geni River, where they reconnoitered the area for 'battue hunting' and also noted its 'rich pasture'. The much-increased harvest that year, noted by Nasutu, had been made possible by the dispatch of the 500 auxiliary boatmen and station cultivators, 'sent out at an expense of grain and silver when cultivating the land'. Nasutu observed that they were burdened by having to 'go back and forth to the postal relay station', possibly to pick up their supplies or to discharge additional duties there. Nasutu's own Dagur, however, had sufficient time and agricultural experience to lend a hand, particularly because they did 'not train in summer'. Nasutu assigned 250 Dagur to help work the

31 MWLF, YZ 11/11/7 [03-0172-0598-005]. 
Geni fields. The rest of the troops would occupy themselves building granaries for the anticipated harvest. Once the crops were in, the troops would do their autumn training, 'so as to benefit both matters of not wasting training time and stockpiling grain on the farthest frontiers'. ${ }^{32}$

\section{The Weight of Multi-environmental Relations Acknowledged}

After three successive years of snow and frost, and five in total of inadequate harvests, however, it was clear by 1736 that a great deal of time and resources had indeed been wasted attempting to establish a stable agrarian foundation for the Hulun Buir garrison. A report by one of the garrison's senior officers, Hadaha, suggested that the agricultural testing project was a failure that could only be redeemed by an exclusive reliance on human resources supplied by pastoral and foraging resources.

Since the Solon and Bargut troops have always hunted and herded and depended on the milk of cattle and sheep for their existence, they can still manage to get by despite the frigid land and regardless of how much snow falls, heavy or light. The Dagur troops all rely on grain fields for their existence. The harvest for four years has been poor, so they have had to buy rice to eat from Qiqihar or seek rice to eat from their relatives in the foraging zone. The place where they live being over $700 b a$ from Qiqihar, the rice they can bring in using their own strength is actually insufficient. So, it is not only that the strength of the Dagur forces in Hulun Buir will be exhausted over time, but also that their relatives who live in the foraging zone will likewise be burdened, to the detriment of their livelihoods. ${ }^{33}$

Cultural and ecological conditions informing the Manchurian borderland, in terms of the Qing empire's three main forms of environmental relations (imperial arablism, imperial pastoralism and imperial foraging), here determine basic policy in Hulun Buir. Although central authorities would have preferred that the garrison depend primarily on grain, the climate dictated that it must instead depend primarily upon game and dairy. Even the elaborate system of grain storage and transport, one of the central mechanisms of imperial arablism, could not overcome Hulun Buir's environmental obstacles, despite enormous stockpiles in strategic towns like Qiqihar, where granaries held at least

\footnotetext{
32 MWLF, YZ 11/11/7 [03-0172-0598-006].

33 MWLF, QL 1/12/11 [03-174-1481-001]. 700 ba (the Manchu word for the basic unit of Chinese linear distance, $(i)$ is about $350 \mathrm{~km}$. The present-day straight-line distance between the cities of Qiqihar and Hulun Buir is about $370 \mathrm{~km}$.
} 
200,000 shi in $1733 .{ }^{34}$ Consequently, any troops dependent on grain supplies could not sustainably be garrisoned in Hulun Buir.

Fortunately for military planners, Qing human resources were multi-environmental enough to adapt. It was initially assumed that environmental relations within the garrison broke down along ethnic lines, as Hadaha described. In 1741, the garrison's senior military officer, Marbai, confirmed this, although in more significant detail. He first stated that, locally, farming and herding were mutually exclusive, suggesting that it was not possible for the garrison to rely on both, even if ecological conditions permitted. Marbai asserted that if cultivators were made to herd, it would put them in great distress. If herders were made to farm, [livestock] reproduction would decline steadily until they became too poor to make a living at it'. Such incompatibility, arising mainly from space constraints, is also visible between Han farmers and Mongol herders in the empire's Six League borderland. ${ }^{35}$

He then affirmed that the Dagur all built dwellings and grew crops. The Solon-Ewenki and Bargut, however, were not only accustomed to herding and hunting, they actively did 'not want to farm'. The main reason for this agrarian aversion, aside from their being 'unfamiliar with cultivation', was that

Hulun Buir itself has fine grasslands and water, and there are also many sorts of wild animals. Since the locality is quite cold, there are early frosts that preclude cultivation. Moreover, because conditions suit the Solon and Bargut livelihood and [stock] breeding very well, they very much hope and desire to stay there.

Marbai endorsed these pastoral and foraging desires, stating that 'in my humble view, in terms of stationing troops it is fitting to consider the natural inclinations of each side. ${ }^{36}$

It is unlikely that anyone involved in these deliberations remembered at least one instructive incident in the Qing historical record of mobilising Manchurian indigenous peoples. A lack of state sensitivity to 'natural inclinations' had triggered a series of desertions among newly recruited Warka groups in 1676 because they had been relocated to an agricultural area devoid of forest game, which some Warka later testified was the main ingredient of their preferred staple of meat broth (M.: yali sile). Within a few weeks of this desertion,

34 MWLF, YZ 11/10/28 [03-0171-0194-014]. The dry-measure unit shi (termed a hule in this Manchu document) is roughly equal to 2.8 bushels or one hectolitre.

36 MWLF, QL 7/3/19 [03-172-610-005]. 
Nigguta's administrators were acknowledging that 'the various newly relocated people are all accustomed to eating meat broth. So, they request meat. Recently, because it is time to cultivate fields, these people have no time to hunt. Consequently, they are unable to obtain meat broth to eat'. Cattle and sheep were specially allocated for this purpose. ${ }^{37}$ The 1676 desertions and negotiations reveal how critical state sensitivity to multi-environmental relations was to the smooth incorporation of a borderland, even one that was ostensibly the dynastic cradle.

Although probably unaware of the circumstances surrounding the 1676 desertions, Marbai took the garrison's preferences seriously enough to propose a re-deployment of the garrison in accordance with its environmental relationships. He wanted to leave the Solon-Ewenki and Bargut foragers in Hulun Buir, but transfer the agrarian Dagur to more amenable fields in another locale, Ombuci. In their deliberation of his proposal, the Grand Council, under Ortai, questioned Marbai's characterisation of the garrison's multi-environmental relations, based on a previous report from Ertu, a former Military Governor of Heilongjiang. Ertu thought the whole garrison 'dependent on grain for its existence. He wanted to base all 3000 troops in the more arable, but not strategic, location of Ombuci, which could also accommodate any pastoral or foraging inclinations, once cultivation duties were discharged, because it had 'fine grasslands and water'. Annually, 1000 troops from the Ombuci garrison would be rotated into Hulun Buir, the best locale to cover the approaches from Russia. $^{38}$

Ertu's views had been persuasive at the time, and the Grand Council had come to believe that

the Solon, Bargut and Dagur are all the same people. While the Dagur are to be returned to their native place because the cold of $\mathrm{HLJ}$ is bad for the grain upon which they depend for existence, the Solon and Bargut likewise all depend on grain for their existence. They absolutely cannot be living on the practice of battue hunting alone. Once they [the Solon and Bargut] know that the Dagur have been sent back, they will suspect that they are treated differently, to the overall detriment of affairs. ${ }^{39}$

37 NFY, KX 2-1676: 39-54, 122-3.

38 MWLF, QL 7/3/19 [03-172-610-005], QL 6/10/5 [03-175-1558-033]. Bao (2012: 83) has understood Ertu to have made an error regarding the environmental relations of the garrison, based on a 'lack of understanding of these troops' living habits'. 
Based on Marbai's new information, however, council officials now acknowledged that they 'plainly [did] not understand local conditions' in Hulun Buir. The then current Military Governor of Heilongjiang, Bodi, was charged to conduct further inquiries to clarify the garrison's environmental relations, along with other administrative matters. ${ }^{40}$ In the process of his long memorial response, Bodi outlined many of the environmental dynamics of the Qing incorporation of its Manchurian borderland that revolved around milk, game and grain.

\section{Concluding Garrison Relations of Milk, Game and Grain}

Bodi affirmed Marbai's rejection of Ertu's solution, but complicated Marbai's own considerably. Bodi actually sent officers to interview the whole garrison and found that some Solon-Ewenki were agrarian and some were hunters. These interviews produced a statistical breakdown of the garrison's multi-environmental dispositions. There were 1308 Solon-Ewenki troops who wanted to live pastorally in Hulun Buir voluntarily, along with 297 Bargut troops; 675 Solon-Ewenki troops and 720 Dagur wanted to live in Ombuci in dwellings and cultivate fields for a living. Ultimately, only 1440 of the original garrison remained in Hulun Buir, where 'grasslands and water in this area are fine, with many wild animals and fish', as foragers. ${ }^{41}$

Most significantly, however, Bodi opposed Ombuci partly on the grounds that the Dagur, despite their dependence on cereals, could not be allowed to subsist totally on grain, because their military skills would decline. This view most directly affirms the multi-environmental identity of the Dagur, who are normally characterised as agricultural, as they were throughout most of the Hulun Buir deliberations. In fact, Qing Dagur identity, as well as some subgroups of Qing Solon-Ewenki identity, depended on both game and grain.

Bodi precisely defined the Hulun Buir garrison, in their pre-deployment capacity as foraging reserve units, as troops who did not receive state provisions and pay, but were self-supporting and obligated to pay sable tribute to the throne. ${ }^{42}$ In this sense, foraging reserve Solon-Ewenki, Bargut and Dagur were

\footnotetext{
40 MWLF, QL 6/10/5 [03-175-1558-033].

41 MWLF, QL 7/3/19 [03-172-610-005].

42 In some administrative respects, the Hulun Buir garrison was different both from Eight Banner regulars and from foraging reserves. When mobilised, foraging reserves were put on half-provisions, unlike their fully provisioned Eight Banner equivalents, to supplement state livestock that was issued to maintain their pastoral lifestyles. Unlike the
} 
all skilled in hunting. Once mobilised, however, they were relieved of hunting tribute, and their multi-environmental character became more significant for official logistics. Once mobilised, the Hulun Buir garrison was 'provided with adequate means of existence', including livestock, 'and formed into state banner companies. They were allocated half-rations on a monthly basis and stationed in Hulun Buir for the express purpose of developing their military skills to make them into a crack unit of elite troops'. Bodi's conceptualisation here emphasises elements of both foraging and pastoralism in the refinement of indigenous human resources into crack imperial troops. ${ }^{43}$

In contrast, agriculture appears largely as an impediment in his evaluation. One of Bodi's other primary objections to rotation from Ombuci was that shifts would change just when plants began to sprout in early spring. Neither the troops coming off rotation, nor those going on rotation (2000 out of 3000 men), would be able to engage in cultivation. The two duties could not be practically reconciled and would preclude cultivation in two out of every three years. ${ }^{44}$ In this instance, human activities could not be adequately attuned to the growth cycles of grass and cereals. This was a critical ecological constraint that created tensions between the cultures of agriculture and pastoralism. Mongol agriculture was the main Inner Asian adaptation to resolve these tensions, but was insufficiently productive for imperial logistical requirements.

Regional conditions in Heilongjiang were generally unfavourable to the state's preferred logistical strategy for borderland occupation, garrison cultivation of local fields. Climate hostile to agriculture restricted regional troop deployments. Bodi plainly laid out this direct connection between nature and culture that required dynastic adaptation:

Frosts are early and the fields not arable. Thus, the troops all rely on Milord's nurturing favour ... Milord annually allocates several hundreds of thousands of silver taels used for the pay and provisions for the officers and men in Heilongjiang ... Since many troops cannot be stationed here where it is cold and fields are few, troops were successively parcelled out as garrisons between two towns of Qiqihar and Mergen built [for that purpose.$^{45}$

\footnotetext{
reserves, however, the garrison came under the direct authority of the Military Governor of Heilongjiang, rather than that of the Lifanyuan (Han 2011: 145-6; 'Liu Zeming' 1993a: $587,590-93)$.

43 MWLF, QL 7/3/19 [03-172-610-005].

44 MWLF, QL 7/3/19 [03-172-610-005].

45 MWLF, QL 7/3/19 [03-172-610-005].
} 
A combination of ecological constraints on troop numbers and regular military demands on their time virtually precluded agriculture, even where it would otherwise have been possible. Bodi argued that low garrison numbers made it difficult enough to go about regular tasks of manning karun outposts, constructing granaries, tracking illicit ginseng diggers and all sorts of corvée obligations, including hunt training. The performance of these duties was continual and left no spare time for troops to farm 'even if fields were fertile and abundant. ${ }^{46}$

Furthermore, agriculture interfered with more viable practices like foraging, a principle demonstrated when Ertu's proposal to relocate the entire garrison to Ombuci had been implemented. The site was so far from proper foraging areas that all the garrison was compelled to harvest grain. Furthermore, conditions were not only 'incomparable to the old homelands where these foragers lived', but, more importantly, were 'incompatible with discharging their obligation to guard critical strategic territory'. Troops really had no local duties to perform in the 'useless and unimportant locale' of Ombuci, which was effectively rendered an inconvenient staging area from which troops would be deployed for tasks elsewhere, resulting 'in a wasteful expenditure of state provisions. ${ }^{47}$

Finally, concerned about the erosive generational effects of cultivation, Bodi wanted to abandon Ombuci, despite its arable advantages, and send its agrarian troops back to the foraging zone. He argued that the presence of boys and young men among the 1395 Solon-Ewenki and Dagur troops working fields in Ombuci would be better prepared for military duties by trapping sable for pelt tribute. 'In this way they would go to their respective homelands and, as before at the appropriate times, cultivate fields, trap sable, hunt, shoot the bow both mounted and on foot, to become completely familiar with being on horseback and inured to hardship. They would become, as usual, an elite group of crack men'. This is a concise description of the foraging zone as an ideal habitat for the construction of a proper Qing military identity refined from the appropriate combination of multi-environmental relations. These relations could certainly include farming, but not at the expense of hunting or herding. Bodi did want garrison troops, those in Hūlan for example, working fields. ${ }^{48}$ Herding and hunting, however, not farming, were the requisite activities to develop Qing soldiers.

Milk and game were more important than grain in the Manchurian borderland to produce bannermen. Grain tended to be associated with state

\footnotetext{
46 MWLF, QL 7/3/19 [03-172-610-005].

47 MWLF, QL 7/3/19 [03-172-610-005].

48 MWLF, QL 7/3/19 [03-172-610-005].
} 
provisioning, which Bodi felt created a serious dependency among mobilised recruits. He noted that 'Manchus in Eight Banner service have become accustomed to depend entirely on' state pay and provisions, but that in recent years such military posts had become difficult to obtain, with a commensurately adverse effect on local livelihoods. As far as Bodi was concerned, the effects of suspending sable tribute to put mobilised troops on state payrolls were already catastrophically evident among the garrison in Būrde. State-supported troops there had no other duties but spring and autumn manoeuvres. So 'they were bound to enter steadily into ease. They stopped the diligent practice of all the old customs of hunting, horsemanship, military skill and endurance of hardship'. Bodi urged that the Būrde garrison likewise be sent back to the foraging zone, where they would 'find that as they diligently hunt and forage (M.: gurgušeme buthašame) for their livelihoods, they will fully mature as men',49

Hunting was, arguably, the central component of Inner Asian masculinity that could not be overlooked during the formation of a Qing military identity in its natural habitat of Manchuria. The significance of this environmental relationship for empire, whether in the form of hunting or of meat eating, was acknowledged by both Han and Inner Asian students of borderland history and policy across dynasties. Indeed, it made the incorporation of the northern reaches of the Manchurian borderland into the Qing empire sustainable, as Bodi's memorial demonstrates in detail. Unlike at points further to the south, Manchurian incorporation was based on human environmental relationships with wild animals and livestock, not domesticated cereals, and so required a fundamentally different imperial identity construct based on foraging and pastoralism, not agriculture. Within these dynamics, Manchu identity was not endangered so much by exposure to cultural Sinification as it was by alienation from environmental ties to game and livestock.

Although agriculture was certainly possible and made critical contributions to Manchurian borderland incorporation, prevailing ecological conditions prevented agriculture from being the primary environmental relationship through which incorporation was sustainably realised. As a Grand Council deliberation of another of Bodi's proposals stated, 'Heilongjiang cultivation is not at all like that of China proper (M.: dorgi ba) in terms of [first] clearing and seasoning fields, then cultivating them. All places selected must be cultivated in rotation'. This was part of a deliberation of his proposals to return 168 Solon-Ewenki and Dagur to trapping tribute sable, after years of 'crude cultivation' of state fields 
in the foraging zone. Troops from the foraging zone may have been agrarian in an Inner Asian sense, but were not really agrarian in a Han, or imperial, sense..$^{50}$

This was a critical cultural distinction for other areas, but would not have mattered in Hulun Buir, whose meagre agricultural potential could not be augmented by human intervention. Instead, there was human adaptation as 2400 more Bargut forager-pastoralists were imported into the remaining original garrison to restore it to its approved strength of around 3000. The rest of Bodi's recommendations were also approved (Bao 2012: 86-7, citing MWLF, QL 7/4/18 [03-171-0230-004]).

There would have been no need for such extended deliberation and adaptation concerning milk, game and grain, which fitfully lasted about a decade, from 1732 to 1742, within the comparative monoculture of China proper where farming, albeit of different types, was the norm for reasons of both culture and nature. In contrast, imperial incorporation of Inner Asian borderlands like Hulun Buir was complicated by a diversity of environmental relations that intermixed hunting and herding with cereal cultivation. Such complications certainly did not prevent dynastic success in this enterprise, but they did reveal the environmental internal contradictions and limits of the Qing endeavour to unite Inner Asia and China proper. The historical results were a much greater diversity of adaptation, identity, ecology and empire than would otherwise have existed under much less expansive Ming conditions. Milk, game and grain were all necessary adaptations for the incorporation of Inner Asian borderlands into the multi-environmental Qing empire.

\section{References}

\section{Archives}

MWLF = Manwen lufu zouzhe [Grand Council Manchu-language reference collection].

Subject category of Manchu holdings in China's History Archive \#1, Beijing, PRC. NFY = Ningguta fudutong yamen dang'an [Ningguta Vice Commander-in-Chief's Office

Archive]. Subject category of Manchu holdings in China's History Archive \#1, Beijing, PRC.

\section{Published Sources}

Asseng, S. 2012. Wheat, in P. Steduto, T.C. Hsiao, E.s Fereres \& D. Raes (eds.), Crop Yield Response to Water: 92-101. (FAo Irrigation and Drainage Paper 66.) Rome: Food and 
Agricultural Organization of the United Nations. http://www.fao.org/land-water/ databases-and-software/crop-information/wheat/en/.

Bao Meihua. 2012. Yongzheng, Qianlong shiqi Hu-lun-bei-er baqi lishi yanjiu [A Study on the Hulunbeir Eight Hushuu' History in Qing Yong Zheng and Qianlong Period (sic)]. PhD dissertation, Neimenggu daxue/Inner Mongolia University.

Bello, David A. 2016. Across Forest, Steppe and Mountain: Environment, identity and empire in Qing China's borderlands. Cambridge: Cambridge University Press.

Bello, David A. Forthcoming. Cultivating Torghut Mongols in a semi-arid steppe.Journal of Chinese History.

Brouwer, C. \& M. Heibloem. 1986. Irrigation Water Management: Irrigation water needs. http://www.fao.org/docrep/s2022e/s2022 e02.htm\#2.4\%2odetermination\%2o of\%2ocrop\%2owater\%2oneeds.

Chan, Hok-Lam. 1988. The Chien-wen, Yung-lo, Hung-hsi and Hsüan-te reigns, 13991435, in F.W. Mote \& D. Twitchett (eds.). The Cambridge History of China, Volume 7 : The Ming Dynasty, Part I: 182-304. Cambridge: Cambridge University Press.

Chen Zilong (ed.). 1997. Huang Ming jingshi wenbian [Collected writings on statecraft from the Ming dynasty]. Beijing: Zhonghua shuju.

Cui Yonghong et al. (eds.). 2010. Qinghai tongshi [A complete history of Qinghai]. Xining: Qinghai renmin chubanshe.

Dai Yi. 1994. Yanjiu Qingshi buke huoque de zhengui shiliao-tuijian Qing Gaozong (Qianlong) yuzhi shiwen quanjji [An indispensable and precious historical source for the research of Qing history-An endorsement of the Imperial compilation of the poems and prose of Qing Gaozong (the Qianlong emperor]. Qingshi yanjiu 2: 109-10.

Dmytryshyn, B., E.A.P. Crownhart-Vaughan \& T. Vaughan (eds.). 1985. Russia's Conquest of Siberia: A documentary record, 1558-170o. Portland (OR): Oregon Historical Society Press.

Fu-heng (comp.). 1990. Pingding Zhun-ge-er fanglüe [Record of the pacification of the Zhughars]. Beijing: Quanguo tushuguan wenxian suoyin fuzhi zhongxin.

Guan Xiaolian \& Qu Liusheng (eds.). 1998. Yongzheng chao manwen zhupi zouzhe quan $y i$ [Complete translation of the Yongzheng court's Manchu language vermilion rescripts]. Hefei: Huangshan shushe.

Gugong Bowuyuan (ed.). 2000a. Qing Gaozong yuzhi shi [Imperial compilation of the poems of the Qianlong emperor of the Qing]. Haikou: Hainan chubanshe.

Gugong Bowuyuan (ed.). 20oob. Qing Shengzu yuzhi shi wen [Imperial compilation of the poems and prose of the Kangxi emperor of the Qing]. Haikou: Hainan chubanshe.

Han Di. 2011. Qingdai Baqi Suo-lun bu yanjiu [Study of the Qing Eight-banner Solon tribes]. Beijing: Zhongguo shehui kexue chubanshe.

Janhunen, J. 1996. Manchuria: An ethnic history Helsinki: Finno-Ugrian Society. 
Liu, M., G. Liu, L. Gong, D. Wang \& J. Sun. 2014. Relationships of biomass with environmental factors in the grassland area of Hulunbuir, China. PLoS One 9(7): e102344.

Liu Xiangxu. 2006. Mingchao minzu zhengci yanbian shi [A history of changes in Ming dynasty ethnic policy]. Beijing: Minzu chubanshe.

'Liu Zeming' (i.e., Yanagisawa Akira). 1993a. Guanyu Hu-lun-bei-er baqi sheli [Concerning the establishment of the Hulun Buir eight banners], in Qingzhu Wang Zhonghan Xiansheng bashi shouchen xueshu lunwen ji [Academic proceedings in celebration of Mr. Wang Zhonghan's eightieth birthday] 585-93. Shenyang: Liaoning daxue chubanshe.

'Liu Zeming' (i.e., Yanagisawa Akira). 1993b. Lüelun Qingchu Hu-lun-bei-er lishi diwei de bianhua ji qi yingxiang [Comments on the transformation of early Qing Hulun Buir's historical status and its effects], in Qingzhu Wang Zhonghan Xiansheng bashi shouchen xueshu lunwen ji [Academic proceedings in celebration of Mr. Wang Zhonghan's eightieth birthday]:576-84. Shenyang: Liaoning daxue chubanshe.

Luo Zhilin (trans.). 2011. Jiangshuai xiuyang de zhuanshi jingdian [Venerable classic for training military commanders], in Zhuge Liang wenji yizhu [Zhuge Liang's works, translated and annotated]. Chengdu: Bashu shushe.

Pavek, P.L.S. 2016. Plant Guide for Buckwheat (Fagopyrum esculentum). Pullman (WA): USDA-Natural Resources Conservation Service. https://plants.usda.gov/core/ profile?symbol=FAES2.

Qi Wenying. 2001. Qingdai Hu-lun-bei-er diqu de liangci yimin yu deshi [Advantages and disadvantages of the two migration periods in the Hulun Buir region during the Qing Dynasty]. Zhongguo bianjiang shi yanjiu 10(1) (Dec): 58-66.

QSL-Qingshilu [Veritable records of the Qing dynasty]. 1985-87. Beijing: Zhonghua shuju.

Shi Lixin. 2005. Shi quan laoren shi quan shi-Qing Gaozong Qianlong de shige chuangzuo [The 'All-round' poetry of the 'All-Conquering Old Man' - The Qianlong emperor Qing Gaozong's poetic creations]. Minzu wenxue yanjiu 4: 29-32.

Su Zhigao. 2006. Yiyu [Comments on the north], compiled in Bo Yinhu \& Wang Xiong (eds.), Mingdai Menggu Han ji shiliao huibian, di yi ji [Compilation of historical materials from Ming dynasty works on Mongolia in Chinese, first series]: 216-37. Hohhot: Nei Menggu daxue chubanshe.

Xiao Daheng. 2006. Beilu fengsu [Customs of the northern barbarians], compiled in Bo Yinhu \& Wang Xiong (eds.), Mingdai Menggu Han ji shiliao huibian, di er ji [Compilation of historical materials from Ming dynasty works on Mongolia in Chinese, second series]: 236-67. Hohhot: Nei Menggu daxue chubanshe.

Yuan Senpo. 1991. Kang, Yong, Qiang jingying yu kaifa beijiang [The management and development of the northern frontier in the Kangxi, Yongzheng and Qianglong reigns]. Beijing: Zhongguo shehui kexue chubanshe. 
Zhang Boying (comp.). 1965. Heilongjiang zhigo [Draft gazetteer of Heilongjiang]. Taibei: Wenahi chubanshe.

Zhang, M.A., E. Borjigin \& H. Zhang. 2007. Mongolian nomadic culture and ecological culture: on the ecological reconstruction in the agro-pastoral mosaic zone in northern China. Ecological Economics 62(1) (April): 19-26.

Zhang Tingyu. 1974. Mingshi [Official history of the Ming Dynasty]. Beijing: Zhonghua shuju.

Zhang Yongjiang. 2003. Liangshi xuqiu yu Qingchu Neimenggu nongye de xingqi [The demand for grain and the rise of agriculture in Inner Mongolia in the early Qing dynasty]. Qingshi yanjiu 3 (Aug.): 32-42.

Zhao Yuntian (ed.). 2006. Qianlong chao neifu chaoben 'Lifanyuan zeli' [Imperial household department draft of the regulations of the Lifanyuan, Qianlong edition]. Beijing: Zhongguo zangxue chubanshe.

Zhe-cang Cai-rang (ed.). 1994. Menggu zu dang'an shiliao jibian [Edited compilation of historical materials from Qing dynasty Qinghai Mongol archives]. Xining: Qinghai renmin chubanshe. 